\title{
Location-Dependent Information Appliances for the Home
}

\author{
Kathryn Elliot, Mark Watson, Carman Neustaedter and Saul Greenberg \\ University of Calgary \\ Calgary Alberta CANADA T2N 1N4 \\ \{elliotk, mwatson, carman, saul\}@cpsc.ucalgary.ca
}

\begin{abstract}
Ethnographic studies of the home revealed the fundamental roles that physical locations and context play in how household members understand and manage conventional information. Yet we also know that digital information is becoming increasingly important to households. The problem is that this digital information is almost always tied to traditional computer displays, which inhibits its incorporation into household routines. Our solution, location-dependent information appliances, exploit both home location and context (as articulated in ethnographic studies) to enhance the role of ambient displays in the home setting; these displays provide home occupants with both background awareness of an information source and foreground methods to gain further details if desired. The novel aspect is that home occupants assign particular information to locations within a home in a way that makes sense to them. As a device is moved to a particular home location, information is automatically mapped to that device along with hints on how it should be displayed.
\end{abstract}

CR Categories: H.5.2 Information Interfaces and Presentation (e.g., HCI): User Interfaces - evaluation/methodology, prototyping, domestic technologies.

Keywords: Domestic technology, location-based design, ambient displays, tangible interfaces, ubiquitous computing, case studies

\section{INTRODUCTION}

Many researchers are now examining the role of routines and places in the management of information in domestic environments [e.g., 3,9,13,25]. They do this to recognize opportunities for new technologies, and to design these technologies so that they fit into the home more naturally, i.e., technology adds value without being disruptive or frustrating.

Our own specific interest is in home communication information, which we define as any item in the home that is used to communicate with other members of the household, or with the outside world from within the home. We already know there is a great deal of paper-based communicative information scattered about in every home: overflowing paper on counter tops and bulletin boards, notes, calendars, reminders, to-do lists, mail, messages, letters, pictures. Far from being 'an unorganized mess', people place information within home locations in a way that optimizes their routines, i.e., how home dwellers collectively amass, track, and use this information $[3,9,13,25]$ (see §2).

Yet we also know that digital information is becoming increasingly important to households. Indeed, information management and display, particularly of dynamic information, is something computers can do very well. The issue is that this digital information is almost always tied to traditional computer displays, which inhibits its incorporation into household routines. People have to 'go to the computer', perhaps located in a out-of- the-way corner of the home, if they wish to do anything with this information. The consequence is that information monitoring is fairly heavyweight, or that household communication is inhibited as people do not receive it in a timely manner.

This introduces a divide. While people have developed excellent strategies for managing conventional information, dynamic and often quite important digital information is difficult to integrate into current home management routines. In part, this is because conventional technologies are work-oriented; this proves a poor fit to the day to day 'business' of running the home and managing all the information within it.

Consequently, our goal is to design information management and display technologies specifically for the home. To achieve this goal, we followed several steps as outlined in this paper. First, we examined ethnographic findings on domestic environments, where we highlight the concept of contextual locations [9] and how these are a critical part of everyday information management in the home (\$2). In particular, we discuss how home dwellers place physical information artefacts at particular locations to display information to others. Second, we consider the design opportunities arising from a class of devices called flexible ambient displays [7] that allow different information sources to be mapped onto its features ( $\$ 3)$. Third, using our understanding of location and routines, we extend the capabilities of these ambient displays to become location-dependent information appliances (§4). In particular, we show how they can be repurposed by location to provide additional value in the home. That is, the placement of the appliance within the home determines what information is shown on it. Fourth, we develop the technical infrastructure behind this concept $(\S 4)$ : we created various physical information appliances differing in form factors and display capabilities; we built hardware that lets these appliances recognize their locations; and we developed a run-time architecture that dynamically maps different information sources onto these displays. Finally, we critique and reflect on this design concept and provide future directions for this work $(\$ 5)$.

We stress up front that this is an 'evaluate/design' paper where design is inspired from previous home ethnographic evaluations. This is only the first part of the larger design process for home technology. This contrasts with standard 'design/evaluate' papers typically found in the HCI literature; we leave this stage for future work. Our design perspective provides three timely contributions. First, we propose an invention of strong potential value, in that it is strongly linked to underlying ethnographically-inspired theories of domestic routine. Second, we contribute an architectural design for building flexible and dynamic information displays for domestic locations. Finally, our design reflections reveal expected uses, critiques, and improvements to our first-cut prototypes.

\section{The Value of Location}

Several studies have examined how communication artifacts are distributed throughout the entire home. As well, the nature of this distribution and its relation to the social organization and activities of a household have been a focus of research $[9,12,25]$. 
The common finding is that domestic communications are socially and physically situated in the routines of the household.

\subsection{Household Routines and Contextual Locations}

Crabtree et al. [3] found that communication media and artifacts moved from one place to another in the home as people interacted with them. They called these locations "places of communication" [3] and defined three sub-types:

- ecological habitats, where artifacts live;

- coordinate displays, where artifacts are left for others; and

- activity centres, where artifacts are worked with. Household members implicitly understand these places and the information within them because they represent an evolved social meaning [3,5]. That is, the way that artifacts in the home are arranged, grouped and moved throughout the space of the home during day-to-day activities form an organizational system for the household $[3,5,24]$.

Taylor and Swan [25] further examined these domestic organizational systems to find that, "heterogeneous collections of artifacts are enrolled to capture, integrate, arrange, and convey information" [25]. The 'work' in the home (e.g., scheduling, errands, chores etc.) relies on these organizing systems. Yet these systems are not static; the family may frequently revise them to meet ongoing requirements. As a result, these systems are often very personalized and idiosyncratic, as they both create and come out of the family's routines. Artifacts used in these systems also move from one location to another [25]. For example, a school letter may be brought home for a parent to read and placed on a countertop. It may then move to a bulletin board for visual reminding, and finally taken to the phone for scheduling.

Importantly, these routines are often collective rather than individual. Most are known by all household members, and actually provide them with resources to manage their activities [3]. The activities people do in the morning when they get up, in the afternoon when they get home from work, and in the evening while they plan for the following day "...provide the grounds whereby the business of home life gets done” [26]. As O'Brien et al. [22] claim: "one of the clearest facets of everyday home life (...) was the importance in all households of 'daily routine', of things 'being as they should be,". While many artifacts are paperbased, digital technologies are now becoming interwoven within these routines [22].

Finally, Elliot et al. [9] investigate the home's places of communication in detail. They found that the household's selection of routine places for information provides its members with valuable context and meta-data about the information placed there. These contextual locations [9] include places such as refrigerator doors, entranceways, living room mantles, and even key racks. These locations allow information to be interwoven with not only action and activities [3,4], but also with time, ownership and awareness: meta-data associated with a location through the routines and patterns of the household [9].

- Time meta-data gives household members a sense of information urgency, dynamics or status [9]. Contextual locations are chosen for when they will be seen. For example, consider items placed by a home's front door: DVDs and library books to be returned, notices to be taken to school, or cheques to be mailed. This placement ensures that they will be seen when people leave the home so they won't be forgotten.

- Ownership is how people know who information belongs to, who is responsible for anything that needs to be done with it, and whether or not they need to pay attention to it. Locations are often chosen for who they are associated with. Some are public: the fridge door is a common example, where the household knows that anything placed there is for everyone to see. Some are personal, such as doorways to bedrooms or piles on a desk: messages placed there are intended primarily for one person. People often place items in such personal locations as requests for actions, as in a child placing a permission slip to be signed on his mother's pile so she'll see and sign it at breakfast. In this way, people also know what actions need to be taken.

- Awareness information is far more subtle. It gives inhabitants a way to monitor and support each other, and lets them know what others are up to. An example is a wife seeing that her husband has not yet paid the bills because they're still in his personal pile on the counter, so she takes on the job of paying them herself. He is then aware she has done this because the bills have moved to a different pile.

Household members combine time, ownership and awareness with their understanding of each others' routines and interactions. From this, they know who a message is for, what actions need to be taken on it, and when they need to see it, by the context of where the message is placed. This location meta-data is a big part of how people manage information in the home.

In summary, ethnographic observations introduce a theory of home organization. People develop routines around the placement of communicative information at locations within a home. These locations add value: awareness at appropriate moments, and knowledge of what information is for, who owns it, who it is intended for, how critical it is, and what actions should be taken.

\subsection{Physical Artifacts as Information Displays}

Information artifacts within the home extend beyond paper [22]; indeed, households appropriate a wide variety of objects to communicate-such as shoes in the doorway or keys on the rack indicating who is home, or laundry piled outside a bedroom assigning a chore $[9,25]$. Regardless of what the artifact is, it is the way objects are normally used that allows people to understand what the different placements of these objects mean.

Several of the studies in $\$ 2.1$ suggest that ubiquitous computing (ubicomp) devices can become a home artifact. Specifically, contextual locations can become prime sites as a way for ubicomp technologies to become incorporated within home practices [3,9]. Example designs include using electronic displays to augment activity centers, or digitally extending coordinate displays to be available outside the home [3,9], e.g., by letting people direct messages to particular locations $[8,29]$. Furthermore, people can appropriate the physical form factor of these devices (if designed appropriately) in valuable ways.

While all this suggests that integrating ubicomp into home locations should be simple, it is actually difficult to do in practice. One issue is that there is a wide range of the kind of places used in the home. To work well, the technology's appearance must aesthetically fit its surrounding physical context, but current limitations of technology-power, space for stands, expense, etc.- - limits what we can now do.

A second issue, and the one directly addressed in this paper, is that it is not enough to simply place fixed-purpose devices into the communication places in the home. For example, consider how easy it is to carry a piece of paper from one room to the next, where its location indicates how the information should be used. Our hypothesis is that ubicomp technology designed for communication in the home needs to make it equally easy to move and repurpose digital devices [24]. Every household has a unique set of places and a unique way of exploiting these places; this implies that people need to be able to map appropriate information onto these locations and appliances. Yet home occupants are not (usually) system administrators [6]. Thus the devices need to be designed in a way that lets people easily configure what information should appear on them.

A variety of information appliances and other tangible devices have already been built, which could act as flexible information 
display for the home. These could include many of the tangible systems designed by Ishii and Ulmer [16], Gaver and Martin's conceptual information appliances [10], or other similar designs found in the literature. Yet these systems all do not currently couple their ability to display ambient information with the routine way that households use locations. That is, they do not allow people to easily repurpose them to display different information when in different contextual locations of the home.

In summary, our premise is that digital artifacts-physical artifacts capable of displaying digital information-should be aware of where they are located, modifying the information they display to suit that location $[9,26]$. Consequently, we believe that technology that home inhabitants can easily move and reconfigure is more likely to be incorporated within the daily routines and social organization of the home [25]. In the rest of this paper, we develop this idea by extending an existing set of flexible ambient display devices to be location-dependent.

\section{AMbient Displays ANd FleXibILITY}

Elliot et al. [7] proposed flexible ambient displays as tangible devices designed around two specific goals. First, they should allow for flexible information sources. They are flexible in that each device can be mapped to a wide variety of information sources (its current implementation requires modest programming to do this). Second, they should provide a smooth transition from awareness into interaction: the ambient qualities of the device provide awareness information, but someone can request more detail by, say, simply touching the device. This allows interaction with the information in the place where it is displayed.

We believe that these ambient displays are especially valuable in the home, as people are not usually sitting in front of a computer all day. People become aware of its information as they move through the home and directly interacting with the device to acquire detail means they do not have to move to their computer to get it. The display's flexible nature means that they could be used (at least in principle) to show the particular information a household is interested in. If the form factor is appropriate, the aesthetics and physicality of ambient devices means that they may fit more naturally into the domestic environment. This is important, as previous work shows that the home itself is a display, where people decorate their homes with things that have meaning to them as a way of imprinting their identities [13]. Therefore, a display that shows information valuable to them may be a welcome addition. Finally, the abstract nature of most ambient displays, where information is codified as lights, motion, etc., mean that only the owners know how to interpret that information. This provides a natural way to protect privacy, something that is especially important when others visit the home.

There are several examples of flexible ambient displays. Elliot et al.'s video [7] illustrates several quite different devices, where each can be repurposed to display differing information, such as Instant Messaging contact status, weather temperature, and 'hits' to a web site. Touching these devices gives further details either as a spoken message, or as a window raised on a nearby computer.

InfoCanvas [21] uses a small LCD panel as an information portrait'. The panel sits on a desk like a picture frame. Users can compose a scene, and add a variety of elements, such as a beach scene with a sun, birds and palm trees. Each element represents some information that is of interest to the user-for instance the color of the sun may represent the user's stock market portfolio, while the number of birds indicate the amount of network traffic. These displays can therefore show a personalized set of information in a way that is meaningful to the user.

Hanger Display [19] is composed of small lights attached to the tops of clothes hangers. When the hangers are in the closet, a percentage of the hangers on a given rack light up to display information. For example, if 6 out of 8 hangers are lit up, it could indicate a $75 \%$ chance of rain. The display is deliberately abstract so that users can choose what type of information to display.

What these displays have in common is that they can allow home occupants to assign information they are interested in to abstract representations. Currently, this assignment is from some data stream to the device; its location does not affect what is displayed. Yet we previously argued in $\$ 2$ that it is the actual location of information that adds significant value. As well, remapping information is currently heavy-weight; either through a graphical user interface or through direct programming. This is not practical in the home.

Our belief is that the act of moving a device from one location to the next should suffice to remap information. Recall that contextual locations [9] show that where information is placed in the home provides household members with valuable context, and that this emerges from peoples' understanding of each other's routines. Thus it would be extremely valuable if digital information could be displayed in the locations people naturally use for information management. This suggests how the concept of flexible ambient displays can be extended: we can use location to decide what information is to be displayed. We call this new genre of displays location-dependent information appliances.

\section{LOCATION-DEPENDENT INFORMATION APPLIANCES}

The premise is that household members are interested in different information as they move to different contextual locations, i.e., particular information appears in those places as people move through their daily routines. If we allow information to be easily assigned to locations, and if our displays can be easily moved to recognize these locations, then they can be repurposed automatically. That is, we can automatically display (different) information relevant to that contextual location on the relocated appliance. Information then benefits from the valuable, even indispensable, context provided by location. These ideas are similar to Humble et al.'s [14] framework for user-configuration of ubicomp environments; however, instead of using software on a single display (e.g., a tablet PC) to configure devices, our model uses the actual physical artifacts in the home and their location for configuration.

We develop this concept by first describing a scenario of use. Next, we show how the system works by describing several appliances we have built, how data streams are constructed, and the idea of smart locations that form the technical underpinnings of location-dependent information appliances.

\subsection{Scenario}

A simple scenario grounds this concept. Consider working parents who set up a location on their bedside table to indicate weather conditions. This information is relevant at this location, as the weather affects how quickly the parents need to get up, wake their child, Jane (a teen), and move Jane through her morning routines. If the weather is bad, Jane takes the bus (which requires less time, letting all sleep in a bit) instead of bicycling to school.

The parents do this by placing a smart locations base (Fig. 1a) on their bedside coffee table, and swiping a weather card over that base (Fig. 1b). They then place an appliance over the base, in this case a floral lamp called FlowerBud (Fig. 1c $+2 d$ ). This appliance contains lights; it is now turned on if the weather is bad, off if it is good. If they touch it, the current weather is spoken through its speakers. If the parents swap out FlowerBud for another appliance (e.g., one of the several shown in Fig. 2), the new appliance will automatically show the weather information, in a form and level of detail appropriate to its capabilities.

As part of her school activities, Jane leaves for a week-long 

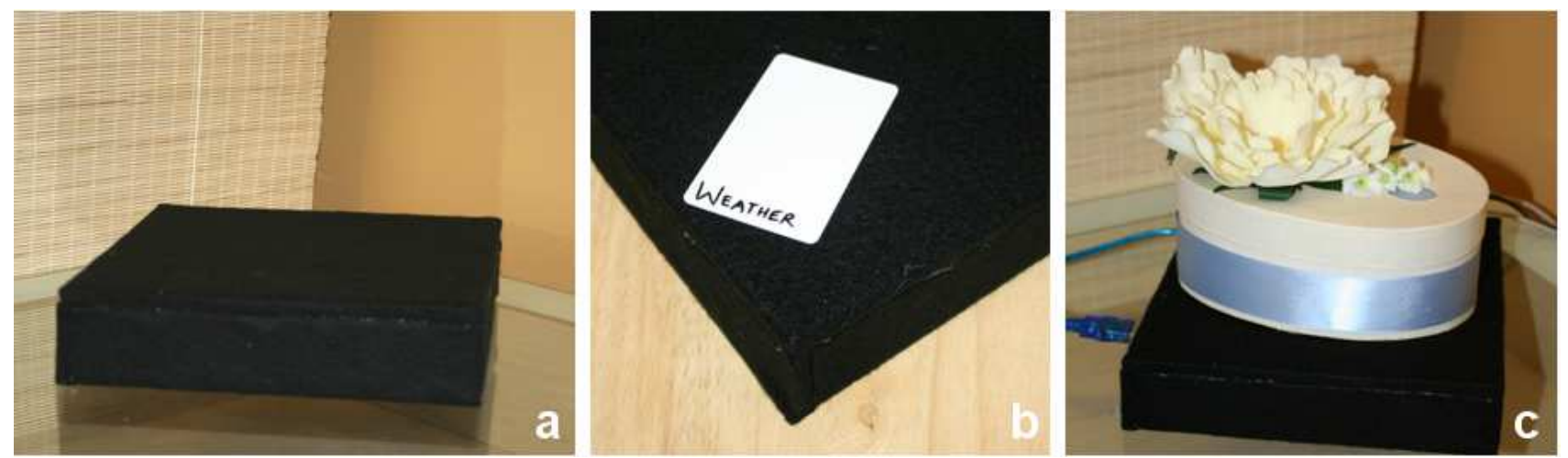

Figure 1. A smart location base, using a information card to assign a data stream to a location, and an appliance placed on a base.
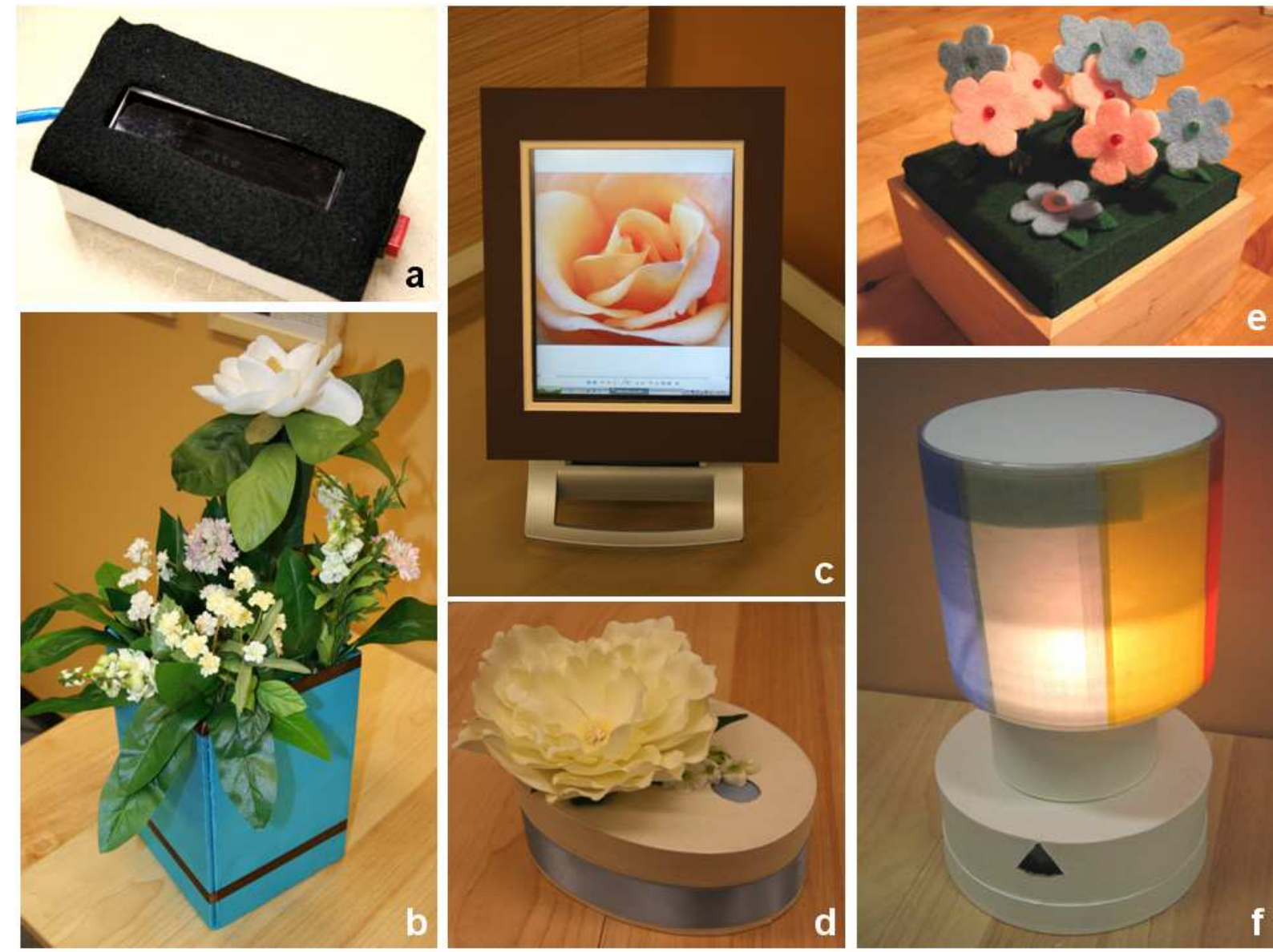

C
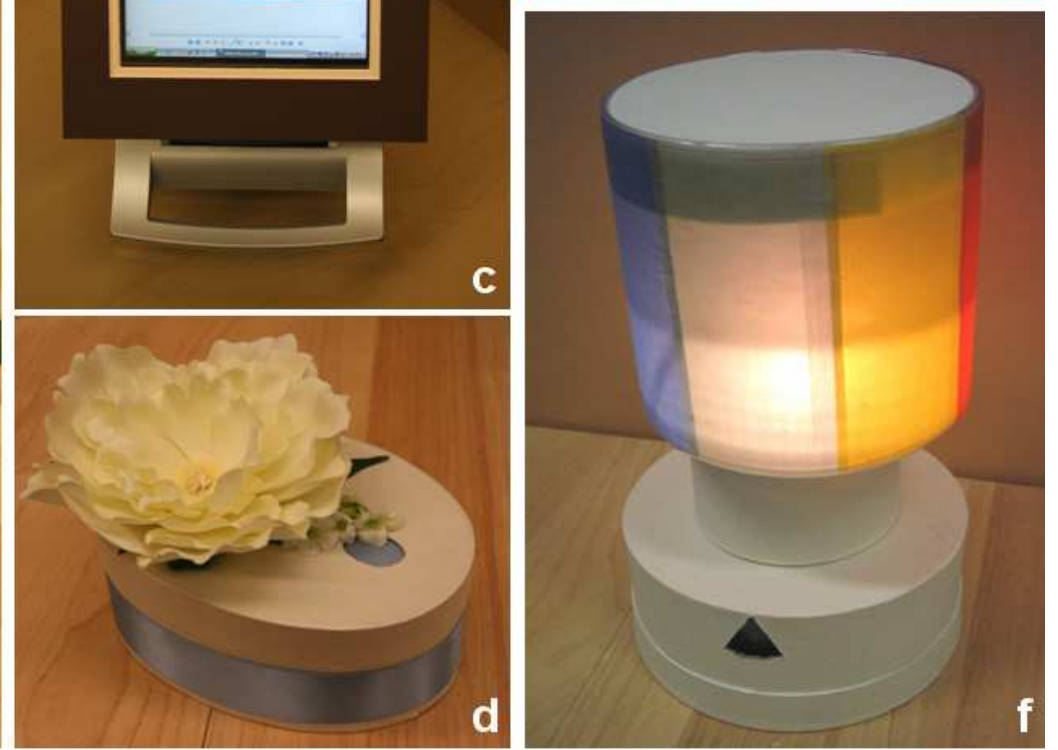

Figure 2. Six Location-Dependent Information Appliances

band trip. The parents want to stay in touch with her via Instant Messaging (IM). They move the FlowerBud appliance to the living room, next to Jane's photo on the fireplace mantle. This location has been configured to show Jane's IM online status, and moving the appliance there causes FlowerBud to light up when Jane is online. Similar to what they did before, the parents do this using an IM information card that they had previously set to Jane's IM contact address.

The parents use other locations in similar ways. When they place an appliance on a counter containing a bill pile, it indicates that some are overdue and thus should be dealt with immediately to avoid interest charges. When they place an appliance by the front entrance way, it indicates that DVDs and / or library books are due; if they touch the device, it gives details on exactly what needs to be dealt with. This use assumes that organizations such as utilities, libraries and video stores provide a notification service that can be tapped into (this is already happening).

\subsection{Appliances}

Our appliances are flexible ambient displays designed to display a wide variety of information sources rather than fixed content. Each also includes 'on demand' capabilities (usually a touch sensor) where people can exploit their awareness by requesting more detailed information from the appliance. A key part of our appliances is that their various display properties - ambient or on demand-are abstracted into one of five representations: 
1. binary: either true or false,

2. discrete: several discrete or distinct states,

3. continuous: a value within a continuous range,

4. textual: purely textual or numerical information,

5. multimedia: could include images, sound, video, links etc. For example, a single light on an appliance may be abstracted as a binary representation (on $=$ true, off $=$ false $)$, while a moving component (e.g., a gauge) may have its position abstracted to display a continuous value in a range. The appliance may have speakers, where it uses speech synthesis to vocalize on-demand information stored as text. The abstract nature of each of these allows the appliance to maintain its information flexibility.

We have built six prototype appliances, illustrated in Fig. 2, where their various display properties are mapped onto one or more of the above five representations. All electronics (with one exception) were built with off-the-shelf Phidgets physical interface hardware components [11]. The appliance's form factor is constructed using readily available prototyping materials, e.g., foam board, wood and cardboard. All appliances also contain RFID tags that identify the type of appliance it is, and thus what kinds of data representations it can handle.

- Text LCD (Fig.2a) is a very simple text display that allows 2 lines of 20 characters each to be shown at once. A button cycles through additional lines.

- Flower in Bloom (Fig. 2b), originally built by Susannah McPhail [20], is a continuous value display consisting of a flower that opens and closes. The degree of the flower bloom (its openness) corresponds to the continuous value.

- Picture Frame (Fig. 2c) is a multimedia display that uses a pen-sensitive Tablet PC embedded in a picture frame.

- FlowerBud (Fig. 2d) is a binary display. Its single flower contains multiple LED lights (to make them visible in well-lit rooms) that can be collectively turned either on or off.

- FlowerPots (Fig. 2e) is a discrete state display consisting of eight LEDs-four red and four green-embedded in the centers of felt flowers. Each light can be lit alone or in combination with others, thus providing many different display states.

- GloLamp (Fig. 2f) is another discrete state display consisting of a small lamp and a rotating shade. The shade has five different coloured panels on it, providing five different states based on which panel is facing front.

\subsection{Data Streams}

To work, each appliance is connected to a data stream that supplies all five data representations. If the appliance is only able to (say) show ambient discrete states and to display (perhaps vocalize) text if it is touched, then the connection software only monitors the ambient discrete property and an on-demand textual representation property held in that data stream. Those values then drive the appliance's specific display properties.

Our strategy is to create a data stream processor client that transforms raw information in a data stream into the abstract data representations that is then published to a server (Fig. 3, top). This transformed data is eventually received by the location client controlling the appliance (Fig. 3, bottom), where that client chooses the format(s) that best match the appliance's display abilities. This makes it so that each data stream can be displayed on a wide variety of appliances.

Specifically, a data stream processor client: (a) taps into particular data sources, (b) decides what data is appropriate for ambient vs. on-demand display, (c) transforms that data into as many of the five abstract representations as possible, (d) publishes the data representations to a distributed data structure-a shared dictionary - that can be subscribed to, and (e) creates a handle to this information so it can be associated with an RFID tag.

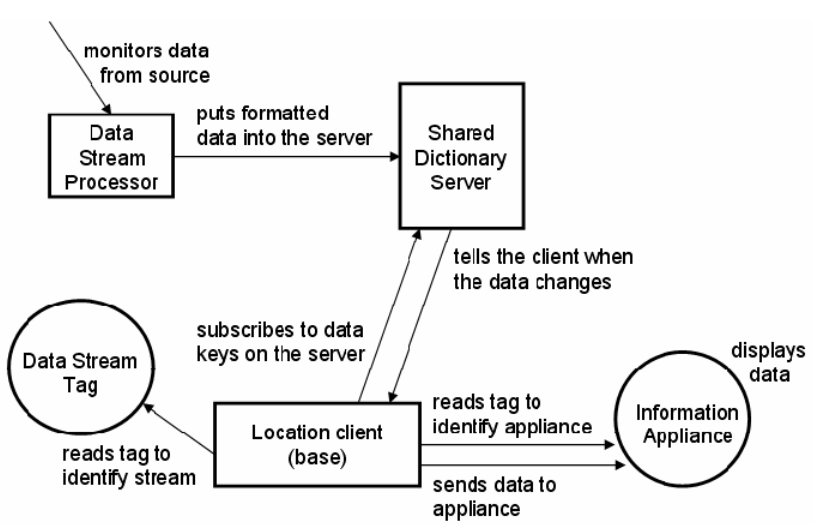

Figure 3. Architecture

While this method is capable of mapping arbitrary data streams to arbitrary appliances, it is somewhat limited in that particular features of an appliance can only be handled in a generic fashion. Consequently, if a particular appliance is known to the system, particular appliance-specific transformations can be encoded within the data stream as well. For example, instead of using the light of the FlowerBud as an on/off binary indicator, the FlowerBud-specific transformation can tell the appliance to flash at a certain rate to illustrate different information states.

To illustrate how all this works in practice, consider how a data stream containing the current weather information is created by the data stream processor. The raw weather information is taken from an RSS feed, or scraped from a web page (perhaps by polling), or arrives through some kind of notification or alerting service. That data is then transformed. For its ambient properties, the binary representation could be true if the current weather is worse than the seasonal norm and false otherwise. A discrete representation could indicate a 4 -state progression from sunny, to sun and clouds, to cloudy, to raining. For a continuous representation, we might map the current temperature, e.g., from 40 to +40 degrees centigrade. Similarly, its on-demand binary property may be rain/not rain, its multimedia property may be a weather map or an image of the HTML weather page, while its textual property may be a weather synopsis. After the data stream client composes this information, it publishes it to a notification server containing a distributed, persistent shared dictionary [2]. The client also lets a person pass an RFID tag over a reader (Fig. 1b), which automatically associates that data with the RFID identifier; we call this a data stream tag. From the user's perspective, this tag becomes an information card-we will explain how this is used shortly. Location clients then subscribe to this information, where they are automatically notified of changes to its data (see below).

\subsection{Smart Locations}

The next part of our architecture uses a location to hook up a data stream to an appliance. Our approach uses smart locations, where the location is aware of information associated with it and what appliance is currently placed on it.

Specifically, each location uses a base - a flat platform with an embedded Phidget RFID tag reader [11] and USB hub hidden in a felt-covered container (to avoid scratching home surfaces), as shown in Fig. 1a and up close in Fig. 4. Each base runs a location client (Fig. 3, bottom middle) that controls how associations are made and how data is gathered and sent to the appliance.

First, a home occupant associates an information source to that location client (Fig. 3, bottom left) by swiping or placing the desired data stream tag on the base, as in Fig. 1b. While this association persists, it can also be changed 'on the fly' whenever a person swipes a new data stream tag over the location base. 


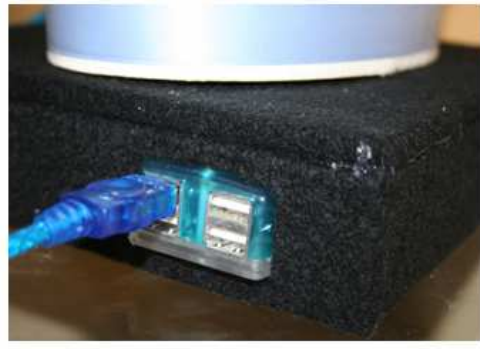

Figure 4. Location base with USB hub.
Second, when a person places an appliance atop or nearby the base (Fig. 1c), the base recognizes that appliance type by reading that appliance's built-in RFID tag (Figure 3 , bottom right).

Third, the location client connects the appliance to the selected information source on the shared dictionary by subscribing to the relevant data abstractions. The location client sees notifications of data changes, and uses these to control the appliance's display. If a person touches the display, the location client looks up the 'on-demand' representations and again uses that to control how the appliance can provide more detailed information.

Smart locations have several advantages that exploit the physicality of the base, the appliance, and the data stream tags. A base can be easily moved to new locations and does not need to know where it is located within the home. Connecting data and appliances is simply a matter of moving things to the base, i.e., there is no need to create a 'map' of the home or use a GUI to assign data to locations and appliances. Managing and recognizing different information sources is simple; labeled data stream tags can be left in the location they are assigned to (as in Fig. 5), and/or they can be stored as a transportable set similar to the samples given for choosing paint colors.

Returning to our scenario in $\$ 4.1$, we now see how that family can intuitively and rapidly configure their environment. They placed one base on the bedside table, and another on the fireplace mantle. Using their set of information cards, they swipe the bedside base with the weather card, and the fireplace mantle base with the IM card. When they place the FlowerBud atop the bedroom base, the base automatically links it to the weather. When they move it to the mantle, that base automatically links it to Jane's IM status. If the parents move (say) the PictureFrame appliance to the fireplace mantle, the base would then send multimedia data to that appliance, e.g., a photo of Jane appears when she is online. If the parents later change things around, e.g., by moving Jane's photo to a new location, they simply move the base with it. The only thing missing is how the IM card knew to link it to Jane; this is done through special software on a conventional computer screen; an RFID reader identifies this IM card, and raises a dialog showing a list of IM contacts it can link to (derived from the current IM settings on that computer).

Because of technical limitations, our current bases and appliances are USB-based rather than wireless; the base currently contains a USB hub, and our prototype appliances are plugged into it (see Fig. 2). Of course, we foresee that these kinds of appliances would eventually require no connections; each base would be wireless, power would be provided by batteries, and a central home computer would host all the software.

As a side note, we recognize that we could have implemented this as a smart appliance instead of a smart location. With smart appliances, physical locations are marked with an RFID tag in addition to tags representing the data streams. Each smart appliance would now contain an RFID tag reader able to read multiple tags. When the smart appliance is placed in a tagged location, it tells the data server to send the data stream associated with that RFID location tag to itself. The advantage of this smart appliance method is that it does not require anything in the chosen locations other than a small tag (e.g. no base). Information thus seems to exist invisibly at the given locations. Mappings could also be performed using a graphic user interface, but this is not necessary. Even though smart appliances represent a viable approach, the need to include RFID tag readers within every device makes smart locations a slightly less expensive approach.

In summary, our design strategy and actual implementation reveals that we can build locationdependent information appliances today, and that their infrastructure need not be overly complex.

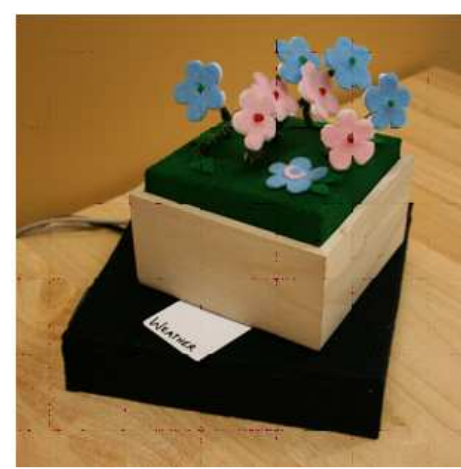

Figure 5. The appliance, base and identifying data stream tag. While our current implementation is wired, wireless and batterypowered systems can be realistically built at modest cost if they are mass produced.

\section{REFLECTION}

\subsection{Scenario revisited}

Imagine a busy family of four and a somewhat more realistic scenario of use. The family has several locations within their home that they use for displaying digital information: the desk containing the phone and family calendar; a placemat on a kitchen counter; the front entranceway; and the living room mantle. When on the phone desk, the FlowerBud glows to show when there have been updates to the online versions of the kids' sport schedulestouching it vocalizes the changes so that parents can conveniently copy these to the calendar. When the season gets especially busy, the parents place the Text LCD or PictureFrame there instead, so they can have more information about the updated schedules at a glance. The family also moves the Text LCD to Dad's placemat at the kitchen counter when he is traveling for work. There it shows text messages that Dad sends the family. Touching it scrolls through the message. A PictureFrame is by the front door: it shows reminders sent by Mom for the kids about what they need to take to various activities, and books and DVDs that have to be returned. A FlowerInBloom sits on the fireplace mantle: it shows Grandma's daily activity level, so that the family knows she's doing well if the flower is in bloom. In this way, these appliances become more valuable in the domestic setting when they are location-dependent, as they are customized to fit into the family's natural routines and pathways through the home. It is through the family's evolved use of the appliances that each family member learns and understands the meanings of the appliances and locations. The appliances become part of the family's normal communication exchanges, and their contextual location within the household's daily routines helps that information make sense.

\subsection{Critique}

While we have painted a rosy picture, there are several concerns that can compromise the use and value of location-dependent information appliances.

First, will people actually position these appliances in a way that exploits location? We anticipate but cannot guarantee that this will happen. We know that physical artifacts are used in this manner, and that existing household technologies like CD players, laptops and even desktop computers $d o$ get moved throughout the home to exploit particular uses in different locations. We also know that new generation commercial technology, such as memory-card based picture frames and mp3 player stands, are being built because there is a perceived market for conveniently displaying and controlling specialize information in appropriate home locations on devices that fit its ecological niche. 
Second, will people actually move appliances from one location to another as needed? We do not believe that these appliances will be regularly carried from one place to another during a single day's routines. Rather, their initial placement will be somewhat dynamic, as families experiment with various locations before finding one that best fits their routines. As well, people may move appliances around to cater to special events, seasonal changes in activities, and short-term interests. Regardless, we need to recognize that device relocation is not a precondition to its success. Ambient displays that stay at a fixed location will have value for they can provide simple and understandable locationbased information representation and interaction in a tangible device. Their ease of setup means they can be easily placed in any home location even if they are rarely moved afterwards.

Third, the industrial design of the appliances becomes a concern when we look at integrating them into the home. Such an appliance would have to smoothly fit into the many different décors. Not all appliances can work in all locations. Lights and glowing screens can be a problem when used in the home at night, especially when in or near bedrooms. Our current prototypes, while very valuable as proof of concept, are not the final solution. They are just crude indicators of how we can move from 'gadgets' to beautiful home objects.

Fourth, a usage concern is whether or not household members will be able to interpret and/or remember what information is being displayed, especially because we anticipate most appliances will be abstract displays like those illustrated in Fig. 2. Ethnographic studies, however, suggest that people will know this association. For example, while people have many sticky notes or piles of papers in their homes, they know what each relates to because of where they are placed. Similarly, people will exploit our appliances' locations as part of their memory of routines. Our implementation also lets people leave data stream tags at the location (Fig. 5), and this could be a further reminder of its function. Further appliance refinements, such as the addition of a small text display to the base, could also indicate what data stream is currently being displayed (although this may compromise aesthetics).

Fifth, our system still requires the creation of small programs to collect, abstract and monitor data streams; we do not solve data collection for the general case. This presents a significant obstacle as most families would not know how to do this. However, we foresee several solutions. First, we believe that a culture of 'sharing' will evolve: a few knowledgeable people will transform data sources and share it with others in the community at large. Such communal sharing is already happened in other domains, e.g., sharing of customization files, code samples, photos, etc. Second, there is technically no problem with creating RSS-like data feeds that abstract information into the five representations mentioned above. The issue here is related to critical mass, where information suppliers need to see a need to do this. Indeed, this is already happening for conventional ambient displays, e.g., the model that Ambient ${ }^{\mathrm{TM}}$ uses for their Ambient Orb [1]. In that system, Orb owners select and personalize what information is displayed from a set made available on the web. A third option is to make the creation of these data streams more amenable to nonprogrammers. For example, the Peripheral Displays Toolkit created by Matthews et al. [18] is designed to help people develop ambient displays for user attention management-especially abstractions, transitions and notification levels. A similar toolkit can be created for our data stream collectors.

Our final concern is that we do not yet know how household members exploit their digital information in the home, how they incorporate it in their routines, or how it will affect their lives. Bringing this information into the home as physical appliances could be valuable and desired, but also overwhelming. Access to and awareness of constantly updating digital information may not be what people actually want in their kitchens, living rooms or hallways. We also cannot predict what changes such availability will bring to existing home routines and culture.

\subsection{Extensions}

We also reflect on ways our work could be extended. One possibility is that devices will not only change the information displayed by location, but also by time-households are interested in different information in different places, and also in different information at different times. Currently, time is used implicitly; i.e., repurposing by location occurs when a person moves the display, or can be done by keeping a few data stream tags near the location and swiping them as information needs change. This could be extended to allow people to explicitly set time-based changes. For example, our scenario in $\S 4.1$ suggests that weather information was valuable at the bedside only in the morning. Perhaps the appliance would change its information in the evening to show (for example) whether any non-routine family activities are scheduled for the morning (suggesting when to set the alarm).

Our appliances are also just examples of what could be. We recognize that the literature shows many other physical displays and uses, and that these could be repurposed to exploit locations. Picture frames, for instance, are a frequent choice for ambient or home information because they are such common and meaningful household artifacts. They could be connected to a remote family member when placed on the mantle, but show family calendaring information in the kitchen. Lamps and other lights, such as Gaver and Martin's [10] DataLamp, are also popular; a lamp could be used functionally as a reading light when placed on a desk, and as a gentle information display when on a shelf. A tablet PC placed by the home entrance could run a reminder system. When moved to the kitchen, it could display a family calendaring program. The Hanger Display [19] could be extended to be locationdependent - for instance, by having hangers show the outside temperature in your bedroom closet (so you can choose appropriate clothing), and when the next bus will be arriving in the downstairs jacket closet (so you know whether or not to rush). Currently, the Hanger Display is not designed in this manner. As an alternative, the Everywhere Displays movable projector [23] could be exploited to project information onto particular locations within a room, where the information content depends on that location's context. Ishii and Ulmer's [16] LiveWire could also be repurposed for the home. When dangling by the home entrance, it could display traffic volumes on one's route to work (lots of motion indicates high volumes). When in the kitchen, it could show the level of activity on a family's calendar for today.

We could also combine our flexible physical appliances with more conventional computer displays to create applications that work in tandem. For instance, FlowerPots could be used to "extend" a location from a home messaging system such as StickySpots [8] or HomeNote [29]. FlowerPots could show the number of new messages in the extended location, and could provide message details when touched, perhaps by displaying it on a nearby television or computer screen.

\subsection{Evaluation}

We have not yet evaluated these appliances within the home; this is future work that must be undertaken. However, we anticipate this evaluation to be difficult. To guide future research, we raise several issues here.

Deploying prototype location-dependent information appliances to the home will be costly. It requires robust software, a solid infrastructure, a no-fail network, and specialized hand-built hardware and appliances. It also requires a good seed set of data stream collector programs or even custom collectors if it is to 
satisfy the particular information needs of a household. This will be time-consuming to create.

Such an evaluation only becomes meaningful when the system is deployed to the home for an extended period of time. Unlike standard 'task oriented' systems, these appliances are cultural artefacts whose real value will emerge only when it is incorporated into the routines and lives of the household. A full evaluation thus needs a longitudinal study of how such appliances fit into these routines, how they change or enhance them as well as where they fail to do so.

We did not do this evaluation as part of our early prototype testing. While we absolutely believe that such an evaluation (while difficult) is important, the kind of design and reflection we have done in this paper is of more immediate value. This reflection helps us consider the role of location in home technology design, and propose how ethnographic study results can be translated into a new genre of appliance - a gap that is not always easy to bridge. This reflection on our first cut prototypes also helps us predict possible successes and failures, correct existing ideas, and suggest new ones. Of course, we expect to feed this reflection back into our system design and usage understanding. Eventually, we will conduct user studies on these more mature technologies, thus making their results more valuable and informative.

\section{Conclusions}

We began with ethnographic studies of the home that revealed the fundamental roles that physical locations and context play in how household members understand and manage conventional information. We then explained how digital information is becoming increasingly important to households, but that the problem is that this digital information is almost always tied to traditional computer displays. This inhibits its incorporation into household routines. We proposed location-dependent information appliances as a solution. These appliances tailor the information they provide to fit within the family's contextual locations, where they provide home occupants with meaningful background awareness of an information source, and foreground methods to gain further details if desired. We also described how it works: home occupants assign particular information to locations within a home in a way that makes sense to them, and devices moved to a particular location automatically shows that information.

For our future work, we will refine our design based on our reflections as stated in $\S 5$. We will also begin a limited deployment: our prototypes will work as technology probes [15] that will help households provide feedback and new ideas as part of a participatory design process. From a technical perspective, we want our devices to be more robust and well-constructed, rather than cardboard prototypes. This needs to happen if they are to survive extended home use. As well, we need to consider wireless and battery-powered alternatives.

\section{REFERENCES}

[1] Ambient ${ }^{\mathrm{TM}}$ commercial product description for the Ambient Orb Available at http://www.ambientdevices.com/cat/orb/orborder.html

[2] Boyle, M. and Greenberg, S. Rapidly Prototyping Multimedia Groupware. Proc. DMS 2005, Knowledge Systems Institute (2005).

[3] Crabtree, A. and Rodden, T. Domestic Routines and Design for the Home. Computer Supported Cooperative Work, Vol. 7. Kluwer Academic Publishers (2004), 191-220.

[4] Crabtree, A., Rodden, T., Hemmings, T. and Benford S. Finding a Place for UbiComp in the Home. Proc. Ubicomp 2003. SpringerVerlag (2003), 208-226

[5] Dourish, P. Re-Space-ing Place: "Place" and "Space" Ten Years On. Proc. of CSCW 2006, ACM Press (2006).

[6] Edwards, W.K. and Grinter, R.E.. At Home with Ubiquitous
Computing: Seven Challenges. Proc. of Ubicomp 2001. SpringerVerlag (2001), 256-272.

[7] Elliot, K. and Greenberg, S. (2004). Building Flexible Displays for Awareness and Interaction. Video Proc. of Ubicomp 2004. The same paper also appears in the Workshop on Ubiquitous Display Environments, held at Ubicomp 2004.

[8] Elliot, K., Neustaedter, C. and Greenberg, S. (2006). StickySpots: Using Location to Embed Technology in the Social Practices of the Home. Proc. of TEI 2007, ACM Press (2007)

[9] Elliot, K., Neustaedter, C. and Greenberg, S.. Time, Ownership and Awareness: The Value of Contextual Locations in the Home. Proc. Ubicomp 2005, Springer-Verlag (2005), 251-268.

[10] Gaver, W., and Martin. H. Alternatives: Exploring Information Appliances through Conceptual Design Proposals. Proc. CHI 2000, ACM Press (2000), 209-216.

[11] Greenberg, S. and Fitchett, C.. Phidgets: Incorporating Physical Devices into the Interface. Proc. UIST 2001, ACM Press (2001).

[12] Harper, R., Evergeti, V., Hamill, L. and Strain, J. Paper-mail in the Home of the 21st Century. Proc. Okios Conference on Digital Technology in Home Environments. (2001)

[13] Hindus, D.. The Importance of Homes in Technology Research. Proc. CoBuild, Springer (1999), 199-207.

[14] Humble, J., Crabtree, A., Hemmings, T., Akesson, K., Koleva, B., Rodden, T., and Hansson, P., "Playing with the Bits": User Configuration of Ubiquitous Domestic Environments, Proc. Ubicomp 2003, Springer-Verlag (2003), 256-263.

[15] Hutchinson, H., Mackay, W., et al. Technology Probes: Inspiring Design for and with Families. Proc. CHI 2003. ACM (2003), 17-24.

[16] Ishii, H., and Ulmer, B. Tangible Bits: Towards Seamless Interfaces between People, Bits and Atoms. Proc. CHI '97, ACM Press (1997).

[17] Kim, S., Kim, M., Park, S. Jin, Y. and Choi, W. Gate Reminder: A Design Case of a Smart Reminder. Proc. DIS 2004. ACM Press (2004), 81-90

[18] Matthews, T., Dey, A.K., Mankoff, J., Carter, S. and Rattenbury, T. A Toolkit for Managing User Attention in Peripheral Displays. Proc. of UIST '04. ACM Press (2004).

[19] Matthews, T., Gellersen, H., Van Laerhoven, K., and Dey, A.K. Augmenting collections of everyday objects: A case study of clothes hangers as an information display. Proc. Pervasive (2004) 340-344.

[20] McPhail, S. and Greenberg, S. The Flower in Bloom. Video at //grouplab.cpsc.ucalgary.ca/phidgets/gallery/flower-in-bloom.html.

[21] Miller, T. and Stasko, J.. The InfoCanvas: Information conveyance through personalized, expressive art. Proc. CHI 2001. ACM Press (2001), 305-306

[22] O'Brien, J., Rodden, T., Rouncefield, M. and Hughes, J. At Home with the Technology: An Ethnographic Study of a Set-Top-Box Trial. ACM TOCHI, Vol. 6(3) (1999), 282-308

[23] Pinhanez, C. The Everywhere Displays Projector. Proc. Ubicomp 2001, Springer-Verlag (2001), 315-331.

[24] Rodden, T., Crabtree, A., et al. Between the Dazzle of a New Building and its Eventual Corpse: Assembling the Ubiquitous Home. Proc. of DIS '04. ACM Press (2004), 71-80.

[25] Taylor, A., and Swan, L., Artful Systems in the Home, Proc. CHI 2005, ACM Press (2005), 641-50.

[26] Tolmie, P., Pycock, J., Diggins, T., MacLean, A. and Karsenty, A. Unremarkable Computing. Proc. CHI 2002, ACM Press (2002), 399-406.

[27] Weiser, M. and Brown, J.S.. Designing Calm Technology. PowerGrid Journal 1, 1, July 1996.

[28] Wisneski, C., Ishii, H., Dahley, A., Gorbet, M., Brave, S., Ullmer, B and Yarin, P.. Ambient Displays: Turning architectural space into an interface between people, bits and atoms. Proc. CoBuild '98. Springer-Verlag (1998).

[29] Sellen, A., Harper, R., Eardley, R., Izadi, S., Regan, T., Taylor, A. S. and Wood, K. R. Situated messaging in the home. Proc CSCW (2006), 383-392. 